\title{
Serological lgG avidity test for ocular toxoplasmosis
}

This article was published in the following Dove Press journal:

Clinical Ophthalmology

31 January 2012

Number of times this article has been viewed

\author{
Subramaniam Suresh' \\ Saidin Nor-Masniwati' \\ Muhd Nor Nor-Idahriani' \\ Wan-Hitam Wan-Hazabbah' \\ Mohamed Zeehaida ${ }^{2}$ \\ Embong Zunaina' \\ 'Department of Ophthalmology, \\ ${ }^{2}$ Department of Medical Microbiology \\ and Parasitology, School of Medical \\ Sciences, Universiti Sains Malaysia, \\ Kelantan, Malaysia
}

Background: The purpose of this study was to evaluate the immunoglobulin (Ig) G avidity of serological toxoplasmosis testing in patients with ocular inflammation and to determine the clinical manifestations of ocular toxoplasmosis.

Methods: A retrospective review of all patients presenting with ocular inflammation to the Hospital Universiti Sains Malaysia, Kelantan, Malaysia between 2005 and 2009 was undertaken. Visual acuity, clinical manifestations at presentation, toxoplasmosis antibody testing, and treatment records were analyzed.

Results: A total of 130 patients with ocular inflammation were reviewed retrospectively. The patients had a mean age of 38.41 (standard deviation 19.24, range 6-83) years. Seventy-one patients $(54.6 \%)$ were found to be seropositive, of whom five $(3.8 \%)$ were both $\operatorname{IgG}$ and $\operatorname{IgM}$ positive (suggestive of recently acquired ocular toxoplasmosis) while one $(0.8 \%)$ showed IgG avidity $\leq 40 \%$ (suggestive of recently acquired ocular toxoplasmosis) and 65 patients $(50.0 \%)$ showed IgG avidity $>40 \%$ (suggestive of reactivation of toxoplasmosis infection). Chorioretinal scarring as an ocular manifestation was significantly more common in patients with seropositive toxoplasmosis $(P=0.036)$. Eighteen patients $(13.8 \%)$ were diagnosed as having recent and/or active ocular toxoplasmosis based on clinical manifestations and serological testing.

Conclusion: Ocular toxoplasmosis is a clinical diagnosis, but specific toxoplasmosis antibody testing helps to support the diagnosis and to differentiate between reactivation of infection and recently acquired ocular toxoplasmosis.

Keywords: ocular toxoplasmosis, chorioretinal scar, toxoplasmosis antibody, IgG avidity test

\section{Introduction}

Ocular toxoplasmosis is the most common cause of posterior uveitis in immunocompetent individuals. ${ }^{1}$ Recognizing the presence of Toxoplasma gondii in the infected eye is difficult and rarely possible unless further investigation is done on aspirated aqueous or subretinal fluid from either an intact or enucleated eye. Despite the availability of various diagnostic methods, ocular toxoplasmosis is often based on clinical manifestations. ${ }^{2,3}$

Ocular toxoplasmosis has a variety of clinical signs and symptoms with various levels of ocular inflammation. ${ }^{4,5}$ The most common feature is focal retinitis or chorioretinitis, where it can manifest as either localized necrotizing retinitis with inflammation of subjacent choroid or an active creamy-white focal retinal lesion. ${ }^{6}$ In Malaysia, the seroprevalence of $T$. gondii is estimated to be around $37.0 \%$ for antitoxoplasmosis antibodies. ${ }^{7}$ Serological testing for specific antibodies has been used as laboratory evidence of the disease, but titration of these antibodies has low reliability 
in ocular toxoplasmosis. Toxoplasma immunoglobulin (Ig) G avidity testing is a qualitative method to improve serological diagnosis of the acute infection with a low avidity index. Low IgG avidity does not always identify a case of recent ocular toxoplasmosis, but a high $\mathrm{IgG}$ avidity result can exclude a primary infection acquired during the previous 5 months. ${ }^{8}$ Thus, it is a powerful tool for distinguishing between recent and distant $T$. gondii infection. ${ }^{9}$ In ocular toxoplasmosis, this IgG avidity assay is helpful for differentiation between reactivation of infection (high $\mathrm{IgG}$ avidity) and recently acquired (low IgG avidity) ocular toxoplasmosis in immunocompetent patients. ${ }^{8}$ The purpose of this study was to evaluate IgG avidity of serological toxoplasmosis testing in cases of ocular toxoplasmosis and to determine the clinical manifestations of the disease.

\section{Materials and methods}

A total of 130 medical records for ocular inflammation cases presenting to the Hospital Universiti Sains Malaysia between 2005 and 2009 were traced. Clinical records were reviewed and data were recorded for each patient, including visual acuity, ocular manifestations at presentation, the serum toxoplasmosis antibody assay result, and treatment given.

An enzyme-linked immunosorbent assay method was used to determine the toxoplasmosis IgG antibody and IgM antibody status for each patient. IgG avidity status was determined using commercial Platelia Toxo IgM, IgG, and $\mathrm{IgG}$ avidity kits (BioRad, France). IgM and IgG use a qualitative assay, while $\operatorname{IgG}$ avidity provides additional information on percentage avidity. The percentage avidity for each positive IgG is calculated according to the manufacturer's instructions. An IgG avidity $>40 \%$ indicates past infection while $\operatorname{IgG}$ avidity $\leq 40 \%$ indicates recent toxoplasmosis infection of $<20$ weeks.

SPSS software version 12 (SPSS Inc, Chicago, IL) was used for the statistical analysis. A descriptive univariate analysis was performed to evaluate frequency of the variables and $T$. gondii antibodies. Possible associations were identified using Chi-squared tests at a significance level of 5\%.

\section{Results}

A total of 130 patients with ocular inflammation were reviewed retrospectively. The patients had a mean age of 38.41 (standard deviation 19.24, range 6-83) years. All patients recruited for this retrospective case series were immunocompetent. The gender and ethnicity distribution is shown in Table 1.
Table I Age and gender distribution of I 30 patients with ocular inflammation

\begin{tabular}{ll}
\hline Variable & $\mathbf{n}=130$ \\
\hline Gender & \\
Male & $72(55.4 \%)$ \\
Female & $58(44.6 \%)$ \\
Age (years) & \\
$\quad$ Mean (standard deviation) & $38.41 \pm 19.24$ \\
Median (range) & $37(6-83)$ \\
Race/ethnicity & \\
Malay & $117(90 \%)$ \\
Non-Malay & $13(10 \%)$ \\
\hline
\end{tabular}

Of the 130 patients, $71(54.6 \%)$ were found to be seropositive, of whom $66(50.8 \%)$ were $\operatorname{IgG}$ positive only and five $(3.8 \%)$ were positive for both IgG and IgM. Sixty-five patients $(50.0 \%)$ were noted to have high IgG avidity $(>40 \%)$ and only one $(0.8 \%)$ showed low IgG avidity $(\leq 40 \%$, Table 2$)$.

Eighteen patients were diagnosed to have ocular toxoplasmosis according to clinical manifestations, and were found to be seropositive (Table 3). Serological testing for ocular toxoplasmosis had a sensitivity of $100 \%$ and a specificity of $53 \%$ to detect ocular toxoplasmosis with ocular inflammation. The positive predictive value was $25.4 \%$ and the negative predictive value was $100 \%$.

Of the 71 patients with seropositive toxoplasmosis, six had results suggestive of recently acquired ocular toxoplasmosis of $<20$ weeks (five patients were positive for both IgM and $\mathrm{IgG}$ and one patient showed $\mathrm{IgG}$ avidity $\leq 40 \%$ ). In the other 65 patients with seropositive toxoplasmosis, ocular inflammation was suggestive of reactivation of toxoplasmosis infection (IgG avidity $>40 \%$ ). We did not analyze the data to identify other causes of ocular inflammation in patients with seronegative toxoplasmosis.

Thirty-two patients (45.1\%) with seropositive toxoplasmosis presented with visual acuity better than $6 / 36$, while 28 patients (39.4\%) had vision worse than $6 / 60$ (Figure 1). Presenting ocular manifestations in patients with seropositive and seronegative toxoplasmosis are shown in

Table 2 Serological toxoplasmosis test for ocular inflammation

\begin{tabular}{lll}
\hline Serological toxoplasmosis test & & $\begin{array}{l}\mathbf{n}=\mathbf{I 3 0} \\
\mathbf{n}(\%)\end{array}$ \\
\cline { 1 - 2 } IgM & IgG & $5(3.8 \%)$ \\
Positive & Positive & $0(0.0 \%)$ \\
Positive & Negative & I $(0.8 \%)$ \\
Negative & Positive avidity $\leq 40 \%$ & $65(50.0 \%)$ \\
Negative & Positive avidity $>40 \%$ & $59(45.4 \%)$ \\
Negative & Negative & \\
\hline
\end{tabular}


Table 3 Serological test to detect ocular toxoplasmosis in ocular inflammation

\begin{tabular}{lll}
\hline $\begin{array}{l}\text { Serological } \\
\text { toxoplasmosis test }\end{array}$ & \multicolumn{2}{l}{$\begin{array}{l}\text { Clinical diagnosis of ocular } \\
\text { toxoplasmosis }\end{array}$} \\
\cline { 2 - 3 } & Yes & No \\
\hline Seropositive & 18 & 53 \\
Seronegative & 0 & 59 \\
\hline
\end{tabular}

Table 4. Chorioretinal scarring was the ocular manifestation present significantly more often in patients with seropositive toxoplasmosis $(P=0.036)$, while an anterior chamber reaction was present significantly more often in patients with seronegative toxoplasmosis $(P=0.046)$.

Based on clinical manifestation and serological testing, $18(13.8 \%)$ patients were diagnosed to have recent and/or active ocular toxoplasmosis infection. However, only $12(66.7 \%)$ were treated with antitoxoplasmosis drugs (Figure 2). In another six patients (33.3\%), no antitoxoplasmosis drug was given because the inflammation had already resolved spontaneously by the time of initiation of treatment. Ocular inflammation resolved with topical steroids in other patients with seropositive toxoplasmosis. We did not investigate for a relationship between IgG avidity and treatment options for seropositive toxoplasmosis.

\section{Discussion}

Of 130 patients who presented with ocular inflammation, $71(54.6 \%)$ had IgG antibodies to T. gondii. This indicates that active or dormant toxoplasmosis is not a rare entity in the Kelantan population in Malaysia. Most of our patients with ocular toxoplasmosis presented before the age of 40 years, which is consistent with the report of Dodds et al of patients presenting before the age of 35 years. ${ }^{10}$

Of the 130 patients with ocular inflammation, 117 presented with blurring of vision and $52.1 \%$ were seropositive for toxoplasmosis. Of these, the majority (45.1\%) presented with vision better than 6/36, and 39.4\%

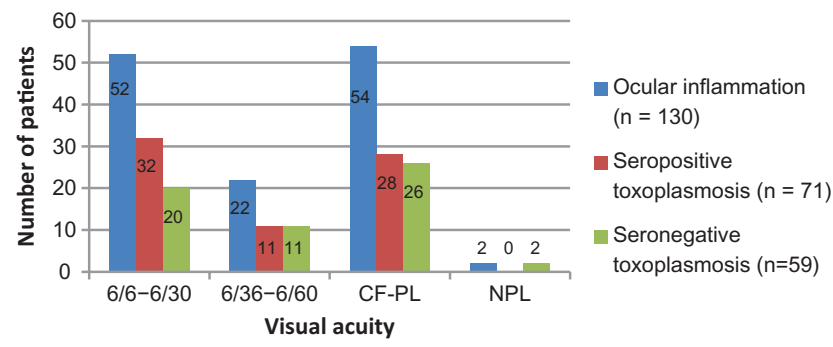

Figure I Visual acuity of affected eye at presentation.

Abbreviations: CF, counting finger; PL, perception of light; NPL, non-perception of light.
Table 4 Ocular manifestations at presentation in patients with ocular inflammation

\begin{tabular}{llll}
\hline Clinical manifestation & \multicolumn{2}{l}{$\begin{array}{l}\text { Toxoplasmosis } \\
\text { serology, n (\%) }\end{array}$} & P value* \\
\cline { 2 - 3 } & \multicolumn{1}{c}{ Positive } & Negative & \\
\hline Blurring of vision & $61(52.1 \%)$ & $56(47.9 \%)$ & 0.089 \\
Redness & $26(20.0 \%)$ & $29(22.3 \%)$ & 0.150 \\
Eye pain & $23(50.0 \%)$ & $23(50.0 \%)$ & 0.434 \\
Headache & $6(37.5 \%)$ & $10(62.5 \%)$ & 0.142 \\
Vomiting & $1(50.0 \%)$ & $1(50.0 \%)$ & 1.000 \\
Floaters & $10(52.6 \%)$ & $9(47.4 \%)$ & 0.851 \\
Anterior chamber reaction & $27(45.0 \%)$ & $33(55.0 \%)$ & 0.046 \\
Vitritis & $19(48.7 \%)$ & $20(51.3 \%)$ & 0.335 \\
Vasculitis & $4(50.0 \%)$ & $4(50.0 \%)$ & 1.000 \\
Choroiditis & $9(52.9 \%)$ & $8(47.1 \%)$ & 0.893 \\
Retinitis & $7(53.8 \%)$ & $6(46.2 \%)$ & 0.908 \\
Chorioretinal scar & $20(76.9 \%)$ & $6(23.1 \%)$ & 0.036 \\
\hline
\end{tabular}

Note: *Chi-square test significant at $P<0.05$.

presented with vision worse than 6/60. Poor vision is one of the common ocular manifestations at presentation in patients with ocular toxoplasmosis. ${ }^{11}$

Ocular inflammation is the main feature indicating the possibility of ocular toxoplasmosis. The presence of chorioretinal scarring raises suspicion of ocular toxoplasmosis. ${ }^{4}$ In this study, 26 patients presented with chorioretinal scarring, about $76.9 \%$ of whom had a seropositive test result. Garweg et al undertook a clinical analysis of ocular toxoplasmosis and found that in patients with a clinical diagnosis of ocular toxoplasmosis, laboratory tests were positive in around $60 \%-90 \%$ of cases. ${ }^{12}$

Consistent with this study, all our 18 patients with a clinical diagnosis of ocular toxoplasmosis were IgG positive but had different levels of avidity. Introduction of the $\mathrm{IgG}$ avidity assay aids diagnosis of toxoplasmosis and helps the clinician to differentiate between reactivation of infection (high $\operatorname{IgG}$ avidity) and recently acquired (low IgG avidity) ocular toxoplasmosis in immunocompetent patients. However, detection of local antibody production from the aqueous or

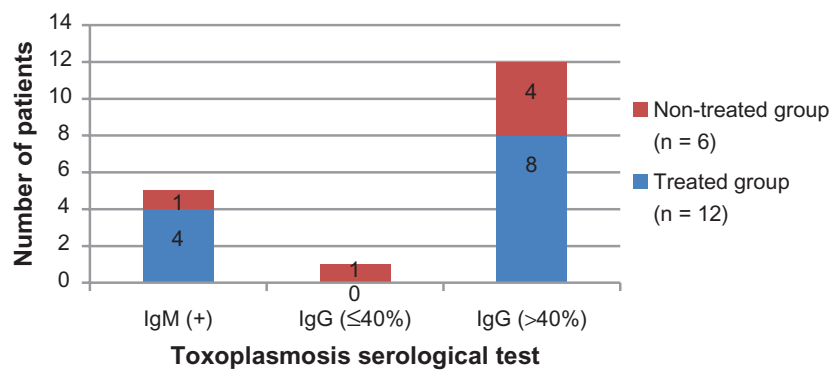

Figure 2 Distribution of patients received anti toxoplasmosis treatment in active ocular toxoplasmosis. 
vitreous humor appears to be more useful in diagnosing ocular toxoplasmosis. We did not undertake antibody detection from the aqueous or vitreous humor in our study.

\section{Conclusion}

Ocular toxoplasmosis is a clinical diagnosis. Antitoxoplasmosis antibody testing helps to establish the diagnosis and to differentiate between reactivation of infection and recently acquired ocular toxoplasmosis.

\section{Acknowledgments}

This study was supported by a university research grant (1001/PPSP/812064) from the Universiti Sains Malaysia.

\section{Disclosure}

This study was presented as a free paper at the Eighth UKM Ophthalmology symposium (July 9-11, 2010), Kuala Lumpur, Malaysia, and at the 15th National Conference on Medical and Health Sciences (July 21-22, 2010), Kelantan, Malaysia. Otherwise, the authors report no conflicts of interest in this work.

\section{References}

1. Vallochi AL, Goldberg AC, Falcai A, et al. Molecular markers of susceptibility to ocular toxoplasmosis, host and guest behaving badly. Clin Ophthalmol. 2008;2(4):837-848.
2. Hogan MJ, Kimura SJ, O'Connor GR. Ocular toxoplasmosis. Arch Ophthalmol. 1964;72(5):592-600.

3. Montoya JG, Parmley S, Liesenfeld O, Jaffe GJ, Remington JS. Use of the polymerase chain reaction for diagnosis of ocular toxoplasmosis. Ophthalmology. 1999;106(8):1554-1563.

4. Nassaji M, Daraie G, Ghorbani R. Clinical feature and treatment outcome of active ocular toxoplasmosis in immunocompetent patients. Asian Pac J Trop Med. 2010;3(7):571-573.

5. Labalette P, Delhaes L, Margaron F, Fortier B, Rouland JF. Ocular toxoplasmosis after the fifth decade. Am J Ophthalmol. 2002;133(4): 506-515.

6. Bosch-Driessen LE, Berendschot TT, Ongkosuwito JV, Rothova A. Ocular toxoplasmosis: clinical features and prognosis of 154 patients. Ophthalmology. 2002;109(5):869-878.

7. Ngui R, Lim YA, Amir NF, Nissapatorn V, Mahmud R. Seroprevalence and sources of toxoplasmosis among Orang Asli (indigenous) communities in peninsular Malaysia. Am J Trop Med Hyg. 2011;85(4): 660-666.

8. Paul M. Immunoglobulin G avidity in diagnosis of toxoplasmic lymphadenopathy and ocular toxoplasmosis. Clin Diagn Lab Immunol. 1999; 6(4):514-518.

9. Villavedra M, Battistoni JJ, Rossi S, Carol H, Nieto A. Avidity analysis of the human immune response to a chitin binding protein of Toxoplasmosis gondii. Int J Parasitol. 2001;31(10):1087-1092.

10. Dodds EM, Holland GN, Stanford MR, et al. Intraocular inflammation associated with ocular toxoplasmosis: relationships at initial examination. Am J Ophthalmol. 2008;146(6):856-865. e2.

11. Kadarisman RS, Marsetio M, Simangunsong LB. Visual impairment and blindness in ocular toxoplasmosis cases. Southeast Asian J Trop Med Public Health. 1991;22 Suppl:99-101.

12. Garweg JG. Determinants of immunodiagnostic success in human ocular toxoplasmosis. Parasite Immunol. 2005;27(3):61-68.
Clinical Ophthalmology

\section{Publish your work in this journal}

Clinical Ophthalmology is an international, peer-reviewed journal covering all subspecialties within ophthalmology. Key topics include: Optometry; Visual science; Pharmacology and drug therapy in eye diseases; Basic Sciences; Primary and Secondary eye care; Patient Safety and Quality of Care Improvements. This journal is indexed on Submit your manuscript here: http://www.dovepress.com/clinical-ophthalmology-journal

\section{Dovepress}

PubMed Central and CAS, and is the official journal of The Society of Clinical Ophthalmology (SCO). The manuscript management system is completely online and includes a very quick and fair peer-review system, which is all easy to use. Visit http://www.dovepress.com/ testimonials.php to read real quotes from published authors. 